\title{
Patient Navigator
}

National Cancer Institute

\section{Source}

National Cancer Institute. Patient Navigator. NCI Thesaurus. Code C48832.

Persons who are trained to guide and support those requiring assistance obtaining medical care. Such persons are sensitive to socio-economic factors within the community and provide a variety of services. Their primary responsibilities are to assist patients that have an abnormal examination or a positive finding to navig ate through the health care system. 